\title{
ANALISIS KETIMPANGAN DAN KLASIFIKASI PEMBANGUNAN EKONOMI KABUPATEN/KOTA DI PROVINSI BANTEN TAHUN 2016-2020
}

\section{INEQUALITY ANALYSIS AND CLASSIFICATION OF ECONOMIC DEVELOPMENT REGENCIES/CITIES IN BANTEN PROVINCE 2016-2020}

\author{
(disubmit 17 April 2021, direvisi 01 Juni 2021, diterima 01 Juni 2021) \\ Noviar ${ }^{1)}$ \\ ${ }^{1}$ BPS Provinsi Banten, Kawasan Pusat Pemerintahan Provinsi Banten \\ J1. Syeh Nawawi Al Bantani, KP3B Palima Serang Banten \\ Corresponding Author: noviar@bps.go.id
}

\begin{abstract}
ABSTRAK
Pelimpahan kewenangan dari pemerintah pusat kepada pemerintah provinsi dan kabupaten/kota untuk menyelenggarakan hampir seluruh fungsi pemerintahan telah menyebabkan kebijakan pembangunan ekonomi disetiap daerah berbeda, mengingat kemajuan dan pertumbuhan ekonomi serta pendapatan perkapita di setiap wilayah juga berbeda-beda. Tujuan dari penelitian ini adalah untuk melihat ketimpangan pembangunan ekonomi dan menentukan klasifikasi wilayah kabupaten/kota di Banten periode tahun 2016-2020 menggunakan pendekatan Indeks Williamson dan Tipologi Klassen. Dari hasil penghitungan Indeks Williamson selama tahun 2016-2020, menunjukkan angka indeks yang selalu berada di atas angka 0,7 dan mendekati angka 1, kondisi ini menunjukkan bahwa ketimpangan pembangunan ekonomi antarkabupaten/kota di Provinsi Banten tidak merata dan terjadi ketimpangan yang cukup tinggi antarkabupaten/kota. Perbedaan konsentrasi kegiatan ekonomi wilayah menjadi salah satu penyebab tingginya ketimpangan pembangunan ekonomi daerah. Berdasarkan hasil penelitian menggunakan analisis Tipologi Klassen, disimpulkan bahwa sebagian besar kabupaten/kota di Banten pada periode 2016-2020 termasuk klasifikasi daerah yang cepat berkembang, yaitu sebanyak lima kabupaten/kota. Selain itu, ada satu daerah termasuk klasifikasi cepat maju dan tumbuh pesat, satu daerah termasuk klasifikasi daerah maju tetapi tertekan, bahkan masih ada daerah yang di bawah rata-rata Provinsi Banten yang masuk kategori daerah relatif tertinggal.
\end{abstract}

Kata Kunci: PDRB, Indeks Wiliamson, Tipologi Klassen

\section{ABSTRACT}

The authority transfer from the central government to the provincial government and regencies/cities in terms of organizing most of the governmental functions has caused different economic development policies in each region, considering that the economic progress and development as well as income per capita in each region is different too. The objective of this research is to review the inequality of economic development and classifying the regencies/cities in Banten Province in the year 2016-2020 by using the Williamson Index and Klassen Typology. The calculation result of Williamson Index during the period of 2016-2020 indicates that the index number is always higher than 0.7 and nearly reaches 1 . This condition shows that the 
economic development in the regencies/cities in Banten Province is not equal and that there has been a high inequality in those regencies/cities. The different concentration of regional economic activites has become a cause of high inequality in the regional economic development. Based on the result of research using the Klassen Typology analysis, it is concluded that most regencies/cities in Banten during the period of 2016-2020 are classified as fast-developing regions, summing 5 (five) regencies/cities. Furthermore, there is one region classified as quickly advanced and grow and rapidly developing, one region classified as developed but under pressure, and even one below-average region in Banten Province classified as relatively lagged.

Keywords: GRDP, Williamson Index, Klassen Typology

\section{PENDAHULUAN}

Berdasarkan Undang - Undang Republik Indonesia No. 32 Tahun 2014 tentang pemerintahan daerah menyebutkan bahwa setiap wilayah, dalam hal ini provinsi maupun kabupaten/kota di Indonesia memiliki kewenangan untuk menyelenggarakan pemerintahan wajib yang berkaitan dengan pelayanan dasar dan bukan pelayanan dasar. Kewenangan tersebut akan menyebabkan kemajuan dan pertumbuhan ekonomi suatu daerah menjadi berbeda karena perbedaan geografis suatu wilayah, kebijakan, dan anggaran pembangunan yang tersedia. Ada daerah yang mampu memacu kegiatan ekonominya sehingga dapat tumbuh pesat, namun di sisi lain ada daerah yang tidak mampu memacu kegiatan ekonominya sehingga siklus ekonominya stagnan atau bahkan terkontraksi menjadi minus pertumbuhan ekonomi. Selain itu, Pendapatan perkapita setiap wilayah tentunya berbedabeda pula, bergantung pada nilai pendapatan (PDRB) dan juga jumlah penduduk di suatu wilayah. Perbedaan wilayah, kebijakan, dan anggaran dalam pembangunan daerah akan mengakibatkan kesenjangan pembangunan antardaerah.
Pembangunan ekonomi adalah proses dimana peningkatan pendapatan riil perkapita penduduk dalam jangka waktu tertentu dengan diikuti perbaikan dari sistem kelembagaan yang ada pada pemerintahan tersebut (Arsyad, 1999).

Menurut Shanti dan Maruto (2007) salah satu target penting dalam pembangunan ekonomi adalah pertumbuhan ekonomi. Oleh karena itu, penting untuk bisa membandingkan tingkat kemajuan suatu wilayah dengan wilayah lainnya menggunakan indikator pertumbuhan ekonomi dan pendapatan perkapita suatu wilayah sehingga kebijakan pembangunan di daerah bisa tepat sasaran sesuai dengan klasifikasi wilayah yang bersangkutan.

Mahardiki (2013) menyatakan bahwa untuk mengatasi kesenjangan pembangunan, pemerintah harus mampu menyeimbangkan antara percepatan pertumbuhan ekonomi dengan pemerataan antardaerah. Salah satu kebijakan yang dapat ditempuh oleh pemerintah adalah dengan memprioritaskan pembangunan daerah yang relatif tertinggal serta memberdayakan peran masyarakat dengan mengelola potensi yang ada di suatu daerah. 
Pemerataan hasil pembangunan mutlak diperlukan agar ketimpangan pendapatan dapat ditekan sehingga tidak menimbulkan kecemburuan sosial yang pada gilirannya bisa menimbulkan gejolak masyarakat dan memicu konflik nasional (Muttaqim, 2014).

Efek perembesan ke bawah dari hasil output secara nasional tidak dapat dinikmati oleh sebagian besar masyarakat sehingga ketimpangan pendapatan masyarakat tidak dapat dihindari (Gama, 2009). Distribusi pendapatan masyarakat dan pembangunan antarwilayah yang tidak merata akan menyebabkan ketimpangan antarwilayah (Sirojuzilam, 2005).

Perbedaan sumberdaya dan faktor produksi yang dimiliki suatu daerah akan menimbulkan ketimpangan pembangunan dan pendapatan penduduk. Daerah yang memiliki sumberdaya dan faktor produksi yang melimpah akan memperoleh pendapatan yang lebih banyak (Yeniwati, 2013).

Menurut Todaro (2000), proses dan tahapan pembangunan suatu wilayah akan berimplikasi kepada ketimpangan pembangunan antarwilayah. Sehingga kemajuan pembangunan suatu wilayah yang berlebihan akan menyebabkan pengaruh yang merugikan mengalahkan pengaruh yang menguntungkan sehingga mengakibatkan ketidakseimbangan pembangunan suatu wilayah.

Farris Adiat dan Achmad Tjachja (2019) menyebutkan bahwa kesenjangan pendapatan antar provinsi di Indonesia mencapai 40 persen dari total provinsi yang ada dan kecenderungannya mengalami peningkatan dari tahun ke tahun. Sementara itu, Wiwiek, A. (2019) menyimpulkan bahwa sebagian besar provinsi di Indonesia pada periode 2014-2018 termasuk dalam klasifikasi daerah yang cepat berkembang.

Sjafrizal (2008) menyebutkan bahwa faktor-faktor yang menyebabkan perbedaan dan ketimpangan pembangunan antarwilayah adalah: (1) Perbedaan sumber daya alam yang dimiliki, (2) Perbedaan letak dan geografis, (3) Perbedaan distribusi barang dan jasa , (4) Perbedaan konsentrasi Konsentrasi kegiatan ekonomi wilayah, (5) Perbedaan anggaran pembangunan antarwilayah. Oleh karena itu, penyusunan perencanaan dan kebijakan pembangunan harus disiapkan dengan baik agar ketimpangan pembangunan antarwilayah dapat diminimalisir.

Sutarno dan Mudrajad Kuncoro (2004) menyebutkan bahwa dalam mengambil kebijakan pembangunan, pemerintah harus memiliki konsep pembangunan berdasarkan spasial yaitu merencanakan pembangunan diarahkan dan diprioritaskan bagi daerahdaerah yang relatif tertinggal dengan tidak melupakan daerah yang lain.

Produk Domestik Regional Bruto (PDRB) merupakan total nilai tambah atas barang dan jasa yang dihasilkan oleh berbagai unit produksi di wilayah tertentu dalam jangka waktu tertentu (biasanya satu tahun). Perkembangan ekonomi suatu wilayah bisa diukur menggunakan indikator laju pertumbuhan yang bisa memperlihatkan tingkat pertumbuhan produksi barang dan 
jasa di suatu wilayah pada periode waktu tertentu. Indikator laju pertumbuhan tersebut merupakan salah satu indikator turunan dari PDRB dengan formula seperti pada persamaan 1. Indikator turunan lain dari PDRB ialah PDRB perkapita yang menunjukkan nilai pendapatan per satu orang penduduk di suatu wilayah pada periode waktu tertentu. Formula untuk menghitung PDRB perkapita di suatu wilayah pada periode waktu tertentu ialah dengan membagi nilai PDRB di suatu wilayah pada periode waktu tertentu dengan total penduduk di suatu wilayah pada periode waktu yang sama. Adapun rumusan untuk menghitung laju pertumbuhan ekonomi sebagai berikut :

$$
\text { Laju Pertumbuhan }=\left(\frac{\text { PDRB }_{t}}{\text { PDRB }_{t-1}} \times 100\right)-100
$$

Keterangan:

$\mathrm{PDRB}_{\mathrm{t}}=$ PDRB Atas Dasar Harga Konstan pada tahun ke $\mathrm{t}$

$\mathrm{PDRB}_{\mathrm{t}-1}=\mathrm{PDRB}$ Atas Dasar Harga Konstan pada tahun ke $\mathrm{t}-1$

\section{METODE PENELITIAN}

\section{Sumber Data}

Data yang digunakan dalam penelitian ini adalah data periode tahun 2016-2020 untuk seluruh kabupaten/kota di Provinsi Banten, mencakup data: 1) Produk Domestik Regional Bruto (PDRB) Atas Dasar Harga Konstan 2010; 2) PDRB Atas Dasar Harga Berlaku menurut Lapangan Usaha; 3) PDRB Perkapita; 4) Jumlah penduduk; 5) Pertumbuhan Ekonomi.

\section{Indeks Williamson}

Metode analisis yang digunakan untuk mengetahui tingkat ketimpangan pendapatan antar kabupaten/kota di Provinsi Banten tahun 2016-2020 adalah Indeks Williamson. Indeks Williamson digunakan untuk mengukur derajat ketimpangan pendapatan antarwilayah melalui pendekatan jumlah penduduk dan PDRB perkapita. Formula ini diperkenalkan oleh Williamson (1965) dengan menjumlahkan selisih PDRB perkapita suatu wilayah dengan wilayah setingkat lebih tinggi, misalnya untuk tingkat kecamatan dengan kabupaten/kota, kabupaten/kota dengan provinsi dan penimbangnya proporsi penduduk suatu wilayah, yang diberi simbol $V w$. Menurut Syafrizal (2012), komposisi utama Indeks Williamson adalah membandingkan tingkat pendapatan perkapita dan jumlah penduduk, yaitu dengan formulasi sebagai berikut :

$$
\boldsymbol{V}_{\boldsymbol{W}}=\frac{\sqrt{\left.\sum\left(\left(\boldsymbol{Y}_{\boldsymbol{i}}-\boldsymbol{Y}\right)^{2}\right)\left(\boldsymbol{f}_{\boldsymbol{i}} / \boldsymbol{N}\right)\right)}}{\boldsymbol{Y}}
$$

Keterangan :

$\mathrm{V}_{\mathrm{w}}=$ Indeks Williamson

Yi $=$ PDRB Perkapita kab/kota atas dasar harga konstan $\mathrm{Y}=$ PDRB Perkapita Provinsi Banten atas dasar harga konstan $\mathrm{f}_{\mathrm{i}}=$ Jumlah Penduduk kab/kota $\mathrm{i}$ $\mathrm{N}=$ Jumlah Penduduk Provinsi Banten Indeks Williamson (tingkat ketimpangan) yang diperoleh terletak antara 0 sampai dengan 1, semakin mendekati 0 (nol) berarti ketimpangan pembangunan antarkabupaten/kota di Provinsi Banten semakin rendah atau dengan kata lain pertumbuhan ekonomi regional terjadi secara 
merata. Jika Indeks Williamson mendekati 1 (satu) maka ketimpangan pembangunan antarkabupaten/kota di Provinsi Banten semakin tinggi serta mengindikasikan adanya pertumbuhan ekonomi regional yang tidak merata.

\section{Tipologi Klassen}

Tipologi Klassen adalah metode analisis dengan membandingkan pendapatan perkapita penduduk dan pertumbuhan ekonomi suatu daerah dengan pendapatan perkapita penduduk dan pertumbuhan ekonomi wilayah satu tingkat lebih tinggi. Indikator utama yang digunakan yaitu pertumbuhan ekonomi dan PDRB perkapita dengan rata-rata pertumbuhan ekonomi pada sumbu vertikal dan rata-rata pendapatan perkapita pada sumbu horizontal yang dipetakan dan terbagi menjadi empat kuadran wilayah, yaitu :

a) Kuadran I. Daerah cepat maju dan cepattumbuh (high growth and high income), yaitu daerah yang memiliki tingkat pertumbuhan ekonomi dan tingkat pendapatan yang lebih tinggi dibanding rata-rata kabupaten/kota.

b) Kuadran II. Daerah maju tapi tertekan (high income but low growth), yaitu daerah yang memiliki pendapatan perkapita lebih tinggi, tetapi tingkat pertumbuhan ekonominya lebih rendah dibanding dengan rata-rata kabupaten/kota.

c) Kuadran III. Daerah berkembang cepat (high growth but income) yaitu daerah yang memiliki tingkat pertumbuhan tinggi tetapi tingkat pendapatan perkapita lebih rendah dibanding rata-rata kabupaten/kota. d) Kuadran IV. Daerah relatif tertinggal (low growth and low income) yaitu daerah yang memiliki tingkat pertumbuhan dan pendapatan perkapita yang lebih rendah dibanding dengan rata-rata kabupaten/kota. Syafrizal (2008) membagi Tipologi Klassen dengan formulasi seperti pada tabel 1.

Tabel 1. Klasifikasi Tipologi Klassen

\begin{tabular}{lll}
\hline \multicolumn{1}{c}{ Yi $>\mathbf{Y}$} & \multicolumn{1}{c}{$\mathbf{Y i}<\mathbf{Y}$} \\
\hline $\mathbf{R}_{\mathbf{i}}>\mathbf{R}$ & $\begin{array}{l}\text { Kuadran 1. } \\
\text { Daerah Maju dan } \\
\text { Tumbuh Pesat }\end{array}$ & $\begin{array}{l}\text { Kuadran 3. } \\
\text { Daerah berkembang } \\
\text { Cepat/Potensial }\end{array}$ \\
$\mathbf{R}_{\mathbf{i}}<\mathbf{R}$ & $\begin{array}{l}\text { Kuadran 2. } \\
\text { Daerah Maju Tetapi } \\
\text { Tertekan }\end{array}$ & $\begin{array}{l}\text { Kuadran 4. } \\
\text { Daerah Relatif } \\
\text { tertinggal }\end{array}$ \\
\hline
\end{tabular}

\section{Keterangan :}

Yi $=$ PDRB Perkapita kab/kota i atas dasar harga konstan $\mathrm{Y}=$ PDRB Perkapita Provinsi Banten atas dasar harga konstan

$\mathrm{R}_{\mathrm{i}}=$ Pertumbuhan Ekonomi kab/kota $\mathrm{i}$

$\mathrm{R}=$ Pertumbuhan Ekonomi Provinsi Banten

\section{HASIL DAN PEMBAHASAN}

\section{Gambaran Umum Ekonomi}

Kondisi perekonomian Banten yang dihitung berdasarkan Produk Domestik Regional Bruto (PDRB) atas dasar harga berlaku sebesar Rp. 626,44 triliun dan PDRB Perkapita sebesar Rp. 47,6 juta. Kondisi pandemi Covid-19 pada tahun 2020 menyebabkan pertumbuhan ekonomi Banten terkontraksi $-3,38$ persen dibandingkan capaian 4 tahun sebelumnya yaitu periode 2016-2019 yang selalu tumbuh diatas 5 persen.

Secara umum gambaran perekonomian di kabupaten/kota pada tahun 2020 bisa dilihat pada tabel 2. Melalui tabel tersebut 
terlihat bahwa Kabupaten Pandeglang memiliki nilai PDRB terrendah yaitu sebesar Rp. 28.492,52 miliar, sedangkan Kota Tangerang memiliki nilai PDRB tertinggi yaitu sebesar Rp.143.840,38 miliar. Sementara jika dilihat dari PDRB perkapita tahun 2020, Kabupaten Lebak memiliki nilai PDRB perkapita terendah yaitu sebesar Rp. 22,22 juta, sedangkan Kota Cilegon memiliki nilai PDRB perkapita tertinggi yaitu sebesar Rp. 233,02 juta, tingginya perkapita Kota Cilegon disebabkan daerah tersebut terkonsentrasi industri manufaktur skala besar yaitu industri logam/baja dan industri kimia.

Kondisi pandemi Covid-19 yang melanda tanah air sejak Maret 2020 berdampak kepada pertumbuhan ekonomi kabupaten/kota di Provinsi Banten yang mengakibatkan ekonomi terkontraksi. Kota Tangerang dan Kabupaten Tangerang menjadi daerah yang paling terdampak yakni dengan rendahnya laju pertumbuhan ekonomi yaitu -6,92 persen dan 3,70 persen. Sementara Kabupaten Pandeglang dan Kabupaten Lebak menjadi daerah tertinggi pertumbuhan ekonomi pada 2020 dengan laju pertumbuhan $-0,54$ persen dan $-0,88$ persen.

Tabel 2. Produk Domestik Regional Bruto (PDRB), PDRB Perkapita, dan Laju Pertumbuhan Tahun 2020

\begin{tabular}{lccc}
\hline Kabupaten/Kota & $\begin{array}{c}\text { PDRB } \\
\text { Berlaku } \\
\text { (Milyar } \\
\text { Rp) }\end{array}$ & $\begin{array}{c}\text { PDRB } \\
\text { Perkapita } \\
\text { (Juta Rp) }\end{array}$ & $\begin{array}{c}\text { Laju } \\
\text { Pertum- } \\
\text { buhan }\end{array}$ \\
\hline 1. Pandeglang & $28.492,52$ & 23,47 & $-0,54$ \\
2. Lebak & $29.076,69$ & 22,22 & $-0,88$ \\
3. Tangerang & $136.005,32$ & 34,79 & $-3,11$
\end{tabular}

\begin{tabular}{lrrr} 
4. Serang & $76.601,09$ & 50,60 & $-1,96$ \\
5. Kota Tangerang & $143.840,38$ & 63,26 & $-16,40$ \\
6. Kota Cilegon & $103.182,06$ & 233,02 & $-0,88$ \\
7. Kota Serang & $31.580,09$ & 45,17 & $-1,29$ \\
8. Kota Tangsel & $82.551,23$ & 45,87 & $-1,01$ \\
\hline BANTEN & $\mathbf{6 2 6 . 4 3 7 , 4 4}$ & $\mathbf{4 7 , 6 0}$ & $\mathbf{- 3 , 3 8}$
\end{tabular}

Sumber : BPS Provinsi Banten

\section{Ketimpangan Wilayah}

Menurut Utami (2018) ketimpangan pendapatan di Provinsi Banten selama tahun 2011-2015 tergolong tinggi diatas ambang batas 0,5 bila dihitung menggunakan Indeks Williamson dan kecenderungan hubungan pertumbuhan ekonomi Provinsi Banten dengan ketimpangan pendapatan antar kabupaten/kota menunjukkan hubungan yang berlawanan.

Perbedaan karakteristik wilayah menyebabkan adanya ketimpangan pembangunan ekonomi dan pendapatan perkapita penduduk antarkabupaten/kota. Besar kecilnya ketimpangan PDRB perkapita antarkabupaten/kota memberikan gambaran tentang kondisi dan perkembangan pembangunan di Provinsi Banten. Ketimpangan pembangunan antarkabupaten/kota yang terjadi di Provinsi Banten selama tahun 2016-2020 dianalisis dengan Indeks Williamson. Hasil perhitungan Indeks Williamson disajikan dalam grafik berikut : 


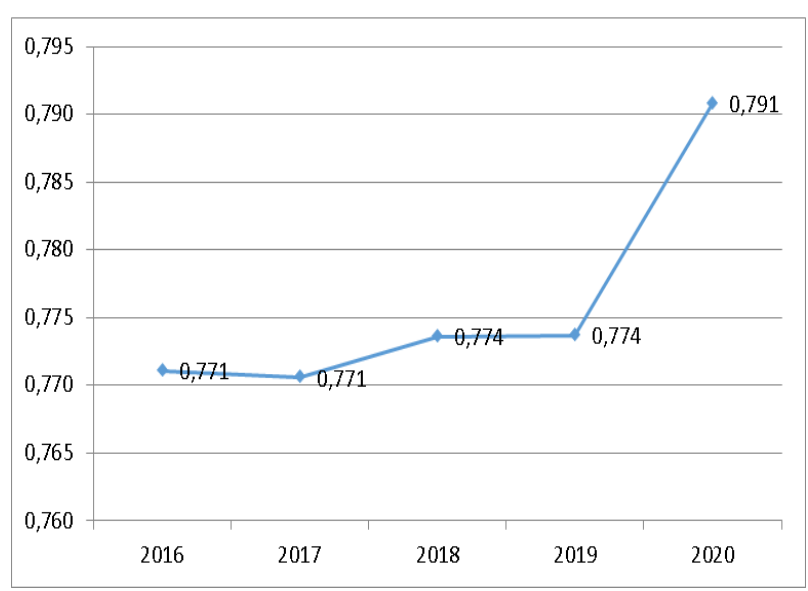

Gambar 1. Indeks Williamson kabupaten/ kota di Banten Tahun 2016-2020.

Sumber : BPS Provinsi Banten (data diolah)

Dari gambar 1. terlihat bahwa nilai Indeks Williamson selama kurun waktu 20162020 selalu berada diatas angka 0,7 dan mendekati angka 1, kondisi ini menunjukkan bahwa ketimpangan distribusi pendapatan perkapita antarkabupaten/kota di Provinsi Banten cukup tinggi atau pertumbuhan ekonomi antardaerah yang tidak merata. Perbedaan pendapatan yang tinggi sudah bisa terlihat dari tabel 2, dimana PDRB perkapita tertinggi adalah Kota Cilegon dengan nilai Rp. 233,02 Juta dan terendah Kabupaten Lebak sebesar Rp. 22,22 Juta.

Selama kurun waktu tersebut terlihat bahwa trend Indeks Williamson setiap tahun cenderung mengalami peningkatan. Tertinggi pada tahun 2020, dimana Indeks Williamson bernilai 0,79. Ketimpangan pendapatan perkapita antardaerah yang cukup tinggi disebabkan konsentrasi kegiatan ekonomi yang tidak merata, salahsatunya perbedaan konsentrasi kegiatan ekonomi wilayah di Banten. Dimana, wilayah Banten Utara yang memiliki basis ekonomi di sektor Industri
Pengolahan dan wilayah Banten Selatan yang memiliki basis ekonomi di sektor pertanian. Berdasarkan distribusi PDRB Provinsi Banten tahun 2020, kontribusi sektor industri pengolahan mencapai 33,45 persen dari total PDRB Banten, sedangkan sektor pertanian menyumbang 5,73 persen.

Konsentrasi kegiatan ekonomi wilayah di Banten menjadi salahsatu penyebab tingginya ketimpangan pembangunan ekonomi. Wilayah Banten Utara yang memiliki basis ekonomi di sektor Industri Pengolahan dan wilayah Banten Selatan yang memiliki basis ekonomi di sektor pertanian. Berdasarkan PDRB Perkapita wilayah perkotaan dan kabupaten yang terdapat konsentrasi kegiatan ekonomi tertentu seperti industri pengolahan yaitu Kota Cilegon, Kota Tangerang, Kabupaten Tangerang, dan Kabupaten Serang memiliki PDRB Perkapita lebih tinggi dibandingkan rata-rata perkapita Provinsi Banten.

\section{Klasifikasi Wilayah}

Dhyatmika (2013) dalam penelitiannya terkait ketimpangan pembangunan di Provinsi Banten pasca pemekaran dari Provinsi Jawa Barat menyebutkan bahwa pertumbuhan ekonomi yang terus meningkat di Provinsi Banten diikuti dengan meningkatnya tingkat ketimpangan pembangunan antardaerah terus meningkat sejak 2001 sampai dengan 2011.

Tabel 3. Hasil Perhitungan Tipologi Klassen Antarkabupaten/kota di Provinsi Banten 20162020. 


\begin{tabular}{llccc}
\hline No & $\begin{array}{c}\text { Kabupaten/ } \\
\text { Kota }\end{array}$ & $\begin{array}{c}\text { Rerata } \\
\text { Pertum- } \\
\text { buhan } \\
\text { Ekonomi } \\
(\%)\end{array}$ & $\begin{array}{c}\text { Rerata } \\
\text { Pendapat- } \\
\text { an } \\
\text { Perkapita } \\
\text { (Juta/Rp) }\end{array}$ & $\begin{array}{c}\text { Kuad- } \\
\text { ran }\end{array}$ \\
\hline 1 & Pandeglang & 4,21 & 21,35 & III \\
2 & Lebak & 4,39 & 20,28 & III \\
3 & Tangerang & 3,77 & 34,31 & III \\
4 & Serang & 3,73 & 46,88 & IV \\
5 & Kota Tangerang & 2,65 & 69,79 & II \\
6 & Kota Cilegon & 4,22 & 220,07 & I \\
7 & Kota Serang & 4,84 & 42,05 & III \\
8 & Kota Tangsel & 5,61 & 43,45 & III \\
\hline & Banten & $\mathbf{3 , 7 4}$ & $\mathbf{4 6 , 9 7}$ & \\
\hline
\end{tabular}

Sumber : BPS Provinsi Banten (data diolah)

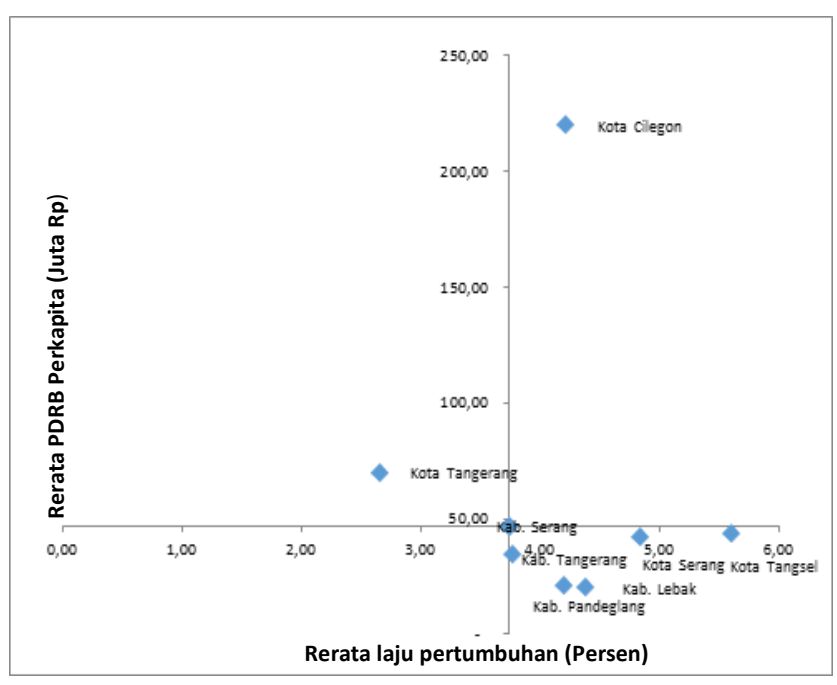

Hasil penghitungan Tipologi Klassen untuk wilayah kabupaten/kota di Provinsi Banten periode 2016-2020 sesuai tabel 3. adalah daerah yang termasuk klasifikasi daerah cepat maju dan tumbuh pesat adalah daerah pada kuadran I yaitu Kota Cilegon, daerah yang memiliki laju pertumbuhan ekonomi dan pendapatan perkapita lebih tinggi jika dibandingkan dengan Provinsi Banten.

Daerah yang masuk pada kuadran II atau termasuk daerah dengan klasifikasi maju tapi tertekan yaitu Kota Tangerang, daerah yang memiliki laju pertumbuhan ekonomi lebih rendah dan pendapatan perkapita lebih tinggi jika dibandingkan dengan Provinsi Banten. Kota Tangerang harus memacu pertumbuhan sektor-sektor lain yang memiliki potensi untuk ditingkatkan selain sektor-sektor ekonomi yang sudah ada. Salah satu sektor yang mulai menurun adalah sektor industri pengolahan, di mana lahan industri di Kota Tangerang sudah tidak dapat dikembangkan lagi karena wilayahnya sudah berbatasan langsung dengan pemukiman penduduk, dan sektor pertanian yang sudah tidak dapat dikembangkan lagi karena lahan yang tersedia sudah beralih fungsi menjadi lahan pemukiman dan perdagangan. Letak Kota Tangerang yang berbatasan dengan Ibukota Jakarta mengakibatkan Kota Tangerang menjadi tempat tinggal bagi masyarakat yang bekerja di ibukota. Oleh karena itu konsentrasi wilayah kegiatan ekonomi berbasis industri pengolahan sudah tidak sesuai sehingga perlu dicarikan sektor lain yang memiliki potensi untuk dikembangkan agar pertumbuhan ekonominya tetap meningkat.

Sementara itu, hasil Indeks Williamson menunjukkan bahwa sebagian besar kabupaten/kota di Provinsi Banten termasuk pada kuadran III yaitu klasifikasi daerah yang memiliki laju pertumbuhan ekonomi lebih tinggi jika dibandingkan dengan laju pertumbuhan ekonomi Provinsi Banten, tetapi PDRB perkapitanya dibawah rata-rata Provinsi Banten. Daerah ini termasuk daerah yang berkembang cepat atau potensial, yaitu Kabupaten Pandeglang, Kabupaten Lebak, 
Kabupaten Tangerang, Kota Serang, dan Kota Tangerang Selatan.

Daerah yang masuk pada kuadran IV yaitu daerah yang memiliki laju pertumbuhan ekonomi dan pendapatan perkapita lebih rendah jika dibandingkan dengan Provinsi Banten. Daerah ini termasuk klasifikasi relatif tertinggal, yaitu Kabupaten Serang. Kebijakan prirotas terhadap daerah yang masuk pada kuadran IV adalah perlu memacu pertumbuhan sektor-sektor ekonomi yang ada baik sektor basis maupun non basis, sehingga pertumbuhan ekonomi dan pendapatan penduduk dapat ditingkatkan.

\section{KESIMPULAN}

Berdasarkan hasil analisis ketimpangan pembangunan ekonomi antarkabupaten/kota menggunakan Indeks Williamson di Provinsi Banten periode 2016-2020, dapat disimpulkan bahwa ketimpangan pembangunan antarkabupaten/kota di Provinsi Banten masih tinggi dan ada kecenderungan mengalami peningkatan.

Beberapa implikasi kebijakan yang bisa disarankan adalah bahwa Pemerintah Provinsi Banten diharapkan dapat memfasilitasi atau memperbaiki faktor-faktor pendukung yang mempengaruhi sektor non basis yang memiliki potensi untuk dikembangkan. Dengan begitu diharapkan sektor non basis tersebut dapat menjadi sektor basis yang berperan dalam peningkatan pertumbuhan ekonomi di masa depan. Pemerintah kabupaten/kota juga diharapkan dapat mendorong dan meningkatkan potensi ekonomi daerah sehingga sumberdaya yang selama ini belum terkelola dapat dimanfaatkan menjadi sumber pendapatan masyarakat sehingga dapat meningkatkan pendapatan masyarakat.

Dengan kebijakan yang prioritas dan tepat sasaran diharapkan pembangunan ekonomi dapat lebih merata antarkabupaten/ kota sehingga dapat meningkatkan pendapatan masyarakat yang pada gilirannya mampu mewujudkan visi Pemerintah Provinsi Banten menciptakan Banten yang Maju, Mandiri, Berdaya Saing, Sejahtera dan Berakhlakul Karimah.

\section{DAFTAR PUSTAKA}

Arsyad, L. (1999). Pengantar Perencanaan dan Pembangunan Ekonomi Daerah Edisi Pertama. Yogyakarta. BPFEYogyakarta.

BPS Provinsi Banten (2021). Produk Domestik Regional Bruto Menurut Lapangan Usaha 2016-2020. BPS.

BPS Provinsi Banten (2021). Produk Domestik Regional Bruto Menurut Pengeluaran 2016-2020. BPS.

BPS Provinsi Banten (2021). Pertumbuhan Ekonomi Banten 2020. Berita Resmi Statistik No. 11/02/Th.XV, 5 Februari 2021. BPS.

Dhyatmika, K, W. (2013). Analisis Ketimpangan Pembangunan Provinsi Banten Pasca Pemekaran. Skripsi Sarjana S-1 Fakultas Ekonomika dan Bisnis Universitas Diponegoro Semarang.

Farris Adiat dan Achmad Tjachja N. (2019). Analisis Kesenjangan Wilayah Dan Kesenjangan Pendapatan Di Indonesia Tahun 2015-2018. E-Jurnal Agribisnis. UIN Syarif Hidayatullah 
Jakarta.

Gama, A, S. (2009). Disparitas dan Konvergensi Produk Domestik Regional Bruto (PDRB) Per Kapita Antar Kabupaten/Kota di Provinsi Bali. Jurnal Ekonomi Dan Sosial (INPUT), 2(1).

Mahardiki, D. dan Rokhedi, P.S. (2013). Analisis Perubahan Ketimpangan Pendapatan dan pertumbuhan Ekonomi Antar Propinsi di Indonesia 2006-2011. Jurnal Ekonomi dan kebijakan (JEJAK) Vol.6 hal: 103-213. No. 1. Fakultas Ekonomi, Universitas Negeri Semarang (Unnes).

Maulana, A. (2019). Analisis Ketimpangan Pembangunan Antarkabupaten/Kota Di Provinsi Kalimantan Selatan Tahun 2010-2017. Jurnal Ilmu Ekonomi Pembangunan Vol.19, No. 1. Fakultas Ekonomi, Universitas Negeri Sebelas Maret.

Muttaqim, H. (2014). Analisis Disparitas Pendapatan Antar Daerah Di Provinsi Aceh Dengan Pendekatan Indeks Ketimpangan Williamson Periode Tahun 2008-2011. Lentera, 14(9).

Sutarno., dan Mudrajad Kuncoro. (2004).

Pertumbuhan Ekonomi dan

Ketimpangan antar Kecamatan di

Kabupaten Banyumas, 1993-2000.

Jurnal Ekonomi Pembangunan.

Shanti, S dan Maruto, U, B. (2007). Disparitas Pendapatan Antar Daerah (Studi Kasus Kabupaten/Kota di Wilayah Pantura Provinsi Jawa Tengah Tahun 19942003). Jurnal Dinamika Pembangunan Vol 4,No 1, hal 33-46. Fakultas Ekonomi, Universitas Diponegoro.

Sirojuzilam. (2005). Beberapa Aspek Pembangunan Regional. Bandung Ikatan Sarjana Ekonomi Indonesia.

Sjafrizal.(2008). Ekonomi Regional, Teori dan Aplikasi. Padang-Baduose Media.

Sjafrizal.(2012).Ekonomi Wilayah dan Perkotaan. Jakarta: Raja Grafindo Persada.

Todaro, M. P. (2000). Economic Development, Seventh Edition. New York: Addition
Wesley Longman, Inc.

Utami, P. R. (2018). Analisis Potensi Ekonomi Daerah dan Ketimpangan Pendapatan Kabupaten/Kota di Provinsi Banten Tahun 2011-2015. Skripsi S-1 Fakultas Ekonomi dan Bisnis. UIN Syarif Hidayatullah Jakarta.

Wiwiek, A. (2019). Analisis Klasifikasi Wilayah Provinsi-Provinsi di Indonesia. Karya Tulis Ilmiah (KTI)Jakarta. BPS.

Yeniwati. (2013). Ketimpangan Ekonomi Antar Provinsi di Sumatera. Jurnal Kajian Ekonomi, 2(3). 